http://jmscr.igmpublication.org/home/ ISSN (e)-2347-176x ISSN (p) 2455-0450 crossref DOI: https://dx.doi.org/10.18535/jmscr/v8i2.65

\title{
Study of aetiology and Clinical Profile in Patients with Atrial Fibrillation
}

\author{
Authors \\ Dr Rajaram Yadav ${ }^{1}$, Dr Madan Paul Singh ${ }^{2 *}$ \\ ${ }^{1}$ Junior Resident, Department of Medicine, Patna Medical College \& Hospital \\ ${ }^{2}$ Professor \& HOD, Department of Medicine, Patna Medical College \& Hospital \\ *Corresponding Author \\ Dr Madan Paul Singh
}

\begin{abstract}
Incidence of AF is Age and Sex related, and ranges from $0.1 \%$ per year before the age of 40 years to higher than $1.5 \%$ year in women and higher than $2 \%$ per year in men older than 80 years. Life time risk of developing $A F$ is approximately $25 \%$ for individuals 40 years old. In Framingham heart study AF developed 1.5 times more in men than in women.

Aims: To find out possible underlying predisposing factors for Atrial fibrillation, both cardiac and noncardiac in our population.

Methods: The present study was conducted upon 60 patients with Atria Fibrillationin the Department of Medicine, Patna Medical College and Hospital, Patna, to find out the varied presenting symptoms of Atrial fibrillation and possible underlying predisposing factors for Atrial fibrillation. Study period was June, 2017 to December, 2019.

Results: People are more likely to be affected by fibrillation between the age of 40 to 60 years. There was female predominance in our study with a male to female ratio of 1.8:1. Palpitation was commonest presenting complaint found in the present study followed by dyspena, chest pain, abdominal pain, tremor, dizziness, and leg swelling. The other complaints were sputum production, thromboembolism, excessive sweating, paralysis. Electrocardiograpic findings showed LA abnormality was the commonest finding followed by left ventricle enlargemnent. Eco-cardiographic impression of the study participants showed rheumatic heart disease is the commonest finding observed among study subjects followed by concentric LV hypertrophy and ischemic heart disease. No significant findings were observed in $8.3 \%$ cases.

Conclusion: RHD, coronary artery disease, hypertension, thyrotoxicosis, COPD, diabetes are the potential risk factors for the occurrence of atrial fibrillation. Majority of the subjects had structural abnormalities in echocardiographic study and left atrial enlargement is a frequent occurrence.
\end{abstract}

\section{Introduction}

$\mathrm{AF}$ is associated with several forms of cardiovascular disease, but may occur in otherwise normal hearts. Cardiovascular factors known to have association with the development of AF include high blood pressure, coronary artery disease, mitral valve stenosis (e.g., due to rheumatic heart disease or mitral valve prolapse), mitral regurgitation, left atrial enlargement, hypertrophic cardiomyopathy (HCM), pericarditis, congenital heart disease, and previous heart surgery. In addition with this, lung diseases (such as pneumonia, lung cancer, pulmonary embolism, and sarcoidosis) are considered to play an important role in certain people. Disorders of breathing during sleep such 
as obstructive sleep apnea (OSA) are also related with $A F .{ }^{[5]}$ Obesity is a risk factor for $A F^{[1]}$ Hyperthyroidism and subclinical hyperthyroidism are also associated with AF development. ${ }^{[2]}$ Caffeine consumption does not appear to be associated with $\mathrm{AF},{ }^{[3]}$ but excessive alcohol consumption ("binge drinking" or "holiday heart syndrome") is very likely related to AF. ${ }^{[4]}$ Sepsis also increases the risk of developing new-onset atrial fibrillation. ${ }^{[5]}$ Long-term endurance exercise (e.g., long-distance bicycling or marathon running) appears to be associated with a modest increase in the risk of atrial fibrillation in middle-aged and elderly people. ${ }^{[6]}$ Tobacco smoking and second hand tobacco smoke exposure are associated with an increased risk of developing atrial fibrillation. ${ }^{\text {[7] }}$

The primary pathologic change observed in atrial fibrillation is the progression of fibrosis of the atria. This fibrosis is caused primarily to atrial dilation; however, genetic causes and inflammation may also be the factors in some individuals. Dilation of the atria can be due to almost any structural abnormality of the heart that can result a rise in the pressure within the heart. This includes valvular heart disease (such as mitral stenosis, mitral regurgitation, and tricuspid regurgitation), hypertension, and congestive heart failure. Any inflammatory state which affects the heart can lead to fibrosis of the atria. This is usually due to sarcoidosis but may also be due to autoimmune disorders that create autoantibodies against myosin heavy chains. Mutation of the lamin AC gene is also associated with fibrosis of the atria that can lead to atrial fibrillation.

AF is associated with an approximately fivefold increase in the risk for stroke and a twofold increase in the risk for all cause mortality. Atrial fibrillation (AF) is a supraventricular arrhythmia which is characterized electrocardiographically by low-amplitude baseline oscillations (fibrillatory or $\mathrm{f}$ waves) and an irregularly irregular ventricular rhythm. The $\mathrm{f}$ waves have a rate of 300 to 600 beats/min and are variable in amplitude, shape, and timing. Long-considered risk factors for $\mathrm{AF}$ include aging, male sex, hypertension, valve disease, left ventricular dysfunction, obesity, and alcohol consumption. Emerging risk factors include prehypertension, increased pulse pressure, obstructive sleep apnea, high-level physical training, diastolic dysfunction, predisposing gene variants, hypertrophic cardiomyopathy, and congenital heart disease. Potential risk factors are coronary artery disease, kidney disease, systemic inflammation, pericardial fat, and tobacco use. AF has substantial population health consequences, including impaired quality of life, increased hospitalization rates, stroke occurrence, and increased medical costs. The pathophysiology of AF centers around 4 general types of disturbances that promote ectopic firing and reentrant mechanisms, and include the following: ion channel dysfunction, $\mathrm{Ca} 2+-$ handling abnormalities, structural remodeling, and autonomic neural dysregulation ${ }^{[8]}$.

\section{Methods}

The present study was conducted upon 60 patients with Atria Fibrillationin the Department of Medicine, Patna Medical College and Hospital, Patna, to find out the varied presenting symptoms of Atrial fibrillation and possible underlying predisposing factors for Atrial fibrillation. Study period was June, 2017 to December, 2019.

\section{Inclusion Criteria}

- Patients aged more than 18yrs.

- Patients with clinically and electrocardiographically proven atrial fibrillation.

\section{Exclusion Criteria:}

- Patients with atrial arrythmias other than atrial fibrillation

- Hemodynamically unstable patients.

\section{Method of collection of data}

1) Detailed history was taken from patient and clinical examination was done according to prepared pro forma. 
2) A twelve lead ECG was done to prove the existence of AF.

3) Patients were subjected for further investigations when indicated-, RBS, RFT, LFT, Thyroid Function Test, Chest X Ray, Echocardiography, Cardiac enzymes, Holter Monitoring, etc.

\section{Results:}

Table 1: Age and Sex Distribution

\begin{tabular}{|l|c|c|c|c|}
\hline $\begin{array}{l}\text { Age } \\
\text { Group } \\
\text { (years) }\end{array}$ & Frequency & Percentage & Frequency & Percentage \\
\hline $\mathbf{3 1 - 4 0}$ & 2 & 9.5 & 6 & 15.4 \\
\hline $\mathbf{4 1 - 5 0}$ & 4 & 19.0 & 6 & 15.4 \\
\hline $\mathbf{5 1 - 6 0}$ & 5 & 23.8 & 9 & 23.0 \\
\hline $\mathbf{6 1 - 7 0}$ & 6 & 28.6 & 12 & 30.8 \\
\hline$>70$ & 4 & 10.0 & 6 & 15.4 \\
\hline Total & 21 & 100.0 & 39 & 100.0 \\
\hline
\end{tabular}

Age and sex distribution of study subjects is shown in Table 1. In our study, 35\% were male patients and $65 \%$ were females. This reflects the female dominance of the disease and current epidemiology of chronic AF. Highest number of cases was seen in 61-70 years age group in case of females and in 40-60 years age group in case of males. The male and female ratio was 1:1.8.

Table 2: Clinical Presentation

\begin{tabular}{|l|c|c|}
\hline Clinical Presentation & Frequency & Percentage \\
\hline Palpitation & 24 & 40.0 \\
\hline Dyspnea & 15 & 25.0 \\
\hline Tremor & 14 & 23.3 \\
\hline Abdominal Pain & 13 & 21.7 \\
\hline Chest pain & 13 & 21.7 \\
\hline Leg Swelling & 12 & 20.0 \\
\hline Dizziness & 13 & 21.7 \\
\hline Sputum Production & 11 & 18.3 \\
\hline Excessive Sweating & 12 & 20.0 \\
\hline Paralysis & 6 & 10.0 \\
\hline Orthopnea & 7 & 11.7 \\
\hline Thromboembolism & 8 & 13.3 \\
\hline Weight Loss & 6 & 10.0 \\
\hline Heat Intolerance & 5 & 8.3 \\
\hline Haemoptysis & 3 & 5.0 \\
\hline
\end{tabular}

Clinical presentation of the study subjects is mentioned in Table 2. Palpitation was commonest presenting problem in majority of cases i.e. $40 \%$ (24) cases. The next common presenting problem was dyspnea (25\%), tremor (23.3\%), chest pain and abdominal pain $(21.5 \%)$.
Table 3: Types of Atrial Fibrillation

\begin{tabular}{|c|c|c|}
\hline Type of AF & Frequency & Percentage \\
\hline $\begin{array}{l}\text { First detected } \\
\text { episode AF }\end{array}$ & 15 & 25.0 \\
\hline \multicolumn{3}{|l|}{ Recurrent episode } \\
\hline $\begin{array}{l}\text { AF and } \\
\text { Paroxysmal AF }\end{array}$ & 11 & 18.3 \\
\hline Persistent AF & 19 & 31.7 \\
\hline Permanent AF & 15 & 25.0 \\
\hline Total & 60 & 100.0 \\
\hline
\end{tabular}

Type of atrial fibrillation among study subjects is mentioned in Table 3. Regarding the type of atrial fibrillation, persistent atrial fibrillation was the most common (31.7\%) in our study subjects followed by permanent atrial fibrillation (25\%). One-forth subjects were detected first time. Less than one-fifth $(18.3 \%)$ subjects were evaluated as recurrent episode or paroxysmal AF.

Table 4: Associated conditions with Atrial Fibrillation

\begin{tabular}{|l|c|c|}
\hline Associated conditions & Frequency & Percentage \\
\hline CCF & 24 & 40.0 \\
\hline Angina & 7 & 11.7 \\
\hline Embolic stroke & 6 & 10.0 \\
\hline Infective endocarditis & 2 & 3.3 \\
\hline
\end{tabular}

The most common associated conditions among study subjects was CCF found in $40 \%$ patients followed by angina found in $11.7 \%$ patients. The other associated conditions were embolic stroke $(10 \%)$ and infective endocarditis (3.3\%). Data is tabulated in Table 4.

Table 5: Chest X-ray Findings

\begin{tabular}{|l|c|c|}
\hline Chest X-ray Findings & Frequency & Percentage \\
\hline No Cardiomegaly & 11 & 18.3 \\
\hline Evidence of Left Atrium Enlargement & 23 & 38.3 \\
\hline Left Ventricle Enlargement & 12 & 20.0 \\
\hline Right Ventricle Enlargement & 17 & 28.3 \\
\hline Prominentpulmonary conus & 19 & 31.7 \\
\hline BiventricularEnlargement & 11 & 18.3 \\
\hline Consolidation ofPneumonitis & 15 & 25.0 \\
\hline
\end{tabular}

Chest X-ray findings of the study subjects is mentioned in Table 5. The most common finding was left atrium enlargement (38.3\%) followed by prominent pulmonary conus (31.7\%), consolidation of pneumonitis (25\%), right ventricle enlargement $(28.3 \%)$, left ventricle enlargement $(20.0 \%)$ and bi-ventricular enlargement (18.3\%). 
Table 6: Electrographic Findings

\begin{tabular}{|l|c|c|}
\hline Electrographic Findings & Frequency & Percentage \\
\hline LA abnormality & 31 & 51.7 \\
\hline LV enlargement & 16 & 26.7 \\
\hline RV enlargement & 9 & 15.0 \\
\hline Left bundle branch block & 7 & 11.7 \\
\hline Left anterior hemi block & 4 & 6.7 \\
\hline Left posterior hemi block & 3 & 5.0 \\
\hline $\begin{array}{l}\text { Non-specific conduction } \\
\text { block ST-Twave }\end{array}$ & 6 & 10.0 \\
\hline $\begin{array}{l}\text { Significant } \\
\text { abnormality Waves }\end{array}$ & 9 & 15.0 \\
\hline Abnormal Q Wa & 8.3 \\
\hline
\end{tabular}

Electrographic findings of the study participants are mentioned in Table 8. The most common finding was left atrium abnormality (51.7\%) followed by left ventricle enlargement (26.7\%), right ventricle enlargement (15\%), significant ST $\mathrm{T}$ wave abnormality (15\%).Other findings were left bundle branch block (11.7\%), non-specific conduction block (10\%), abnormal Q waves (8.3\%), left anterior hemi block (6.7\%) and left posterior hemi block $(5 \%)$.

Table 7: Echocardiographic Impression

\begin{tabular}{|l|c|c|}
\hline $\begin{array}{l}\text { Echocardiographic } \\
\text { Impression }\end{array}$ & Frequency & Percentage \\
\hline Rheumatic heart disease & 28 & 46.7 \\
\hline Ischaemic heart disease & 7 & 11.7 \\
\hline $\begin{array}{l}\text { Concentric } \\
\text { hypertrophy }\end{array}$ & 11 & 18.3 \\
\hline Dilated cardiomyopathy & 3 & 5.0 \\
\hline Cor pulmonale & 6 & 10.0 \\
\hline No significant finding & 5 & 8.3 \\
\hline Total & 60 & 100.0 \\
\hline
\end{tabular}

Table 7 shows the eco-cardiographic impression of the study participants. Rheumatic heart disease is the commonest finding (46.7\%) followed by concentric LV hypertrophy (18.3\%), ischemic heart disease $(11.7 \%)$, Cor pulmonale (10\%) and dilated cardiomyopathy (5\%). No significant findings were observed in $8.3 \%$ cases.

\section{Discussion}

In the present study, AF was seen more common in the 40-60 years age group. This is in accordance to that reported by other authors. According to Lip Gy, Golding DJ majority of people fibrillated after the age of 50 years ${ }^{[9]}$.
Epidemiological studies have shown that AF is fairly uncommon in people aged under 50 years but is found in $0.5 \%$ of people of aged 50-59, increasing to $8.8 \%$ at age $80-89^{[10]}$. PT Onundarson et al showed that the prevalence of chronic AF is low in randomly selected population 32-64 years of age ${ }^{[11]}$.

The mean age of the patients in this study was $54.68 \pm 17.48$ years which was slightly less than that of patients enrolled in AFFIRM study ${ }^{[12]}$, with the mean age of $69.7 \pm 9.0$. In study by Gurpal Singh et al mean age was 51.68 years ${ }^{[13]}$. In another study of prevalence and management of AF Stewart FM et. al ${ }^{[14]}$, mean age of the patients was 76 years.

Dilated cardio-myopathy (DCM) was seen in $3(5 \%)$ of the patients. Diagnostic criteria for dilated cardio-myopathy was adopted as left ventricular ejection fraction $<40 \%$, LVEDD> $112 \%$ of predicted and fractional shortening $<25 \%$. According to Singh et.al ${ }^{[13]}$, DCM was found in $22.72 \%$ patients. In AFFIRM study cardio-myopathy was predominant diagnosis in $5 \%$ of the patients ${ }^{[12]}$.

Thyrotoxicosis was found in $4(6.7 \%)$ of the patients in this study. Other clinical features present in these patients, were heat intolerance, tremor, warm and moist palms. In Gurpal Singh et.al, Thyrotoxicosis was found in $9.09 \%$ of the patients $^{[13]}$. Krahn AD et.al ${ }^{[15]}$ stated that thyroid disease is an unusual and sometimes overlooked cause of AF, occurring in about $2 \%$ of patients ${ }^{[16]}$. In $3(5 \%)$ patients Pneumonia was the associated condition with AF in this study. In Stewart et.al study, pneumonia was the cause for admission in $17 \%$ of the patients ${ }^{[14]}$.

Most common abnormality recorded was dilated left atrium. Majority of the study subjects (70\%) had dilated left atrium (> $4 \mathrm{~cm}$ ). Similar higher rates of structural abnormalities including dilated left atrium were also reported by Kumar and Soodan ${ }^{[17]}$ and Nand et al.27 In a study by Nanda et al, ${ }^{[18]} 62.1 \%$ had their left atrial size more than $3.5 \mathrm{~cm}$ and valvular heart disease; particularly mitral stenosis $(47 \%)$ and dilated 
cardiomyopathy $(90.09 \%)$ were the main causes of enlarged left atrium. Kumar and Soodan ${ }^{[17]}$ also had reported dilated left atrium in $68 \%$ subjects. These findings are consistent with those reported by ALFA study ${ }^{[16]}$.

Left atrial dilatation is a marker of chronicity and severity of left ventricular dysfunction and also the degree of increased LA pressure. LA size assessment plays a significant role in atrial fibrillation and transthoracic echocardiography is particularly helpful in assessing left atrial size. Normal LA size should be less than $40 \mathrm{~mm}$, and those with LA size more than $45-50 \mathrm{~mm}$ have been shown to be at risk of developing AF. Dilated LA is associated with stroke and also the risk of relapse after electrical cardioversion or after radiofrequency ablation is done. Left atrial enlargement is common in AF, particularly in patients with mitral valve disease, left ventricular dilatation, annular calcification or hypertension ${ }^{[19]}$. In addition, sustained AF itself can lead to a further increase in left atrial size, an effect that is reversible after cardioversion and maintenance of sinus rhythm. About $20-30 \%$ of all strokes are due to AF. Results from ROCKET-AF trial sub study done by BA Steinberg et al. show that among patients with $\mathrm{AF}$ at moderate to high risk of stroke of receiving anticoagulation, those with persistent AF have a higher risk of thromboembolic events and worse survival compared with paroxysmal $\mathrm{AF}^{[19]}$

\section{Conclusion}

Patients with RHD etiology presented with AF in middle age, Female patients were more common then male patients. Most common symptom in our study was palpitation. Most common etiology was Rheumatic heart disease. Large group of subjects may still be asymptomatic as well. Persistent AF and permanent AF are the important form of atrial fibrillation.RHD, coronary artery disease, hypertension, thyrotoxicosis, COPD, diabetes are the potential risk factors for the occurrence of atrial fibrillation. Majority of the subjects had structural abnormalities in echocardiographic study and left atrial enlargement is a frequent occurrence

\section{References}

1. Magnani JW, Hylek EM, Apovian CM (23 July 2013). "Obesity begets atrial fibrillation: a contemporary summary". Circulation. 128 (4): 401-05.

2. Palmeiro C, Davila MI, Bhat M, Frishman WH, Weiss IA (December 2013). "Subclinical hyperthyroidism and cardiovascular risk: recommendations for treatment". Cardiology in Review. 21 (6): 300-08.

3. Cheng, M; Hu, Z; Lu, X; Huang, J; Gu, D (April 2014). "Caffeine intake and atrial fibrillation incidence: dose response metaanalysis of prospective cohort studies". The Canadian Journal of Cardiology. 30 (4): 448-54.

4. Tonelo D, Providência R, Gonçalves L (August 2013). "Holiday heart syndrome revisited after 34 years". Arquivos Brasileiros de Cardiologia. 101 (2): 18389.

5. Kuipers, S; Klein Klouwenberg, PM; Cremer, OL (December 2014). "Incidence, risk factors and outcomes of new-onset atrial fibrillation in patients with sepsis: a systematic review". Critical Care (Systematic Review). 18(6): 688.

6. Wilhelm, M (August 2014). "Atrial fibrillation in endurance athletes". European Journal of Preventive Cardiology. 21 (8): 1040-48.

7. Du, X; Dong, J; Ma, C (April 2017). "Is Atrial Fibrillation a Preventable Disease?". Journal of the American College of Cardiology (Review). 69 (15): 1968-82.

8. Fuster V, Rydén LE, Cannom DS, et al. ACC/AHA/ESC 2006 Guidelines for the Management of Patients With Atrial Fibrillation: A Report of the American College of Cardiology/American Heart Association Task Force on Practice 
Guidelines and the European Society of Cardiology Committee for Practice. Circ., 2006; 114(7): e257-e354.

9. Lip GY. Golding DJ - A survey of atrial fibrillation in general practice. British Jr. of general practice. 1997; 47 (418) 285 289.

10. Lip GY, Beevers DG. ABC of atrial fibrillation: History, epidemiology, and importance of atrial fibrillation. BMJ 1995; 311:1361.

11. P .T. Onundarson, G.Thorgeirsson, E.Jonmundsson, N.Sigfusson and Th.Hardarson. Chronic atrial fibrillationepidemiologic features and 14 year followup: A case control study. Eur Heart J. 1987; 8(5): 521-527.

12. Baseline characteristics of patients with atrial fibrillation: The AFFIRM Study. American Heart Journal 2002; 143(6):9911001.

13. Gurpal Singh et.al. A study of 66 patients of atrial fibrillation (AF)-Clinical and Etiological review. $\mathbf{J}$ of Association of Physicians of India 2001; 49.

14. Stewart FM, Singh Y, Persson S, Gamble GD, Braatvedt GD. Atrial fibrillation: prevalence and management in an acute general medical unit. Australian and New Zealand J Med 1999; 29(4): 568.

15. Krahn AD, Klein GJ, Kerr CR, et al: How useful is thyroid function testing in patients with recent-onset atrial fibrillation? The Canadian Registry of Atrial Fibrillation investigators. Arch Intern Med 1996; 156: 2221-2224.

16. Levy S, Maarek M, Coumel $P$ et al. Characterization of different subsets of atrial fibrillation in general practicein France: the ALFA study. The College of French Cardiologists. Circulation 1999; 99: 3028-35.
17. Kumar T, Soodan SS. Clinical and echocardiographicprofile of atrial fibrillation. JK Science 2011;13(2):73-5

18. Nanda V, Gupta AK, Mahmood SE et al. Etiologicalprofile and clinical presentation of patients with atrialfibrillation from a rural area of Bihar. National Journal ofMedical Research 2012; 2(2):124-7.

19. HK Chopra, GS Wander, Praveen Chandra, Viveka Kumar. Atrial Fibrillation Update - A textbook of Cardiology, First edition, 2017, p. 262263. 